\title{
Aspectos celulares da cicatrização *
}

\author{
Cellular aspects of wound healing
}

Ricardo José de Mendonça ${ }^{1}$
Joaquim Coutinho-Netto ${ }^{2}$

Resumo: O processo cicatricial compreende uma sequência de eventos moleculares e celulares que interagem para que ocorra a restauração do tecido lesado. Desde o extravasamento de plasma, com a coagulação e agregação plaquetária até a reepitelização e remodelagem do tecido lesado o organismo age tentando restaurar a funcionalidade tecidual. Assim, este trabalho abrange os diversos aspectos celulares envolvidos no processo cicatricial, bem como os principais medicamentos utilizados no tratamento de patologias relacionadas às deficiências na cicatrização. São abordados também, os aspectos econômicos referentes, sobretudo, às feridas crônicas de pés diabéticos.

Palavras-chave: Agentes indutores da angiogênese; Cicatrização de feridas; Permeabilidade capilar

Abstract: Wound healing is a dynamic interactive process that involves a sequence of molecular and cellular events. Recent advances in cellular and molecular biology have greatly expanded our understanding of the biological process involved in wound repair and tissue regeneration. From plasma extravasation, with coagulation and platelet aggregation, to reepithelialization and remodeling of injured tissue, the organism acts by trying to restore functionality tissue. Thus, the present study encompasses several cellular aspects involved in the wound healing process, as well as the main drugs used in treating the pathology related to wound healing complications. Economic aspects are also addressed, mainly related to chronic wounds of diabetic feet.

Keywords: Angiogenesis inducing agents; Capillary permeability; Wound healing

\section{INTRODUÇÃO}

Os custos dos tratamentos de patologias relacionadas à deficiência cicatricial aumentam a importância dos estudos em busca de medicamentos e curativos capazes de interagir com o tecido lesado, tendo por objetivo acelerar o processo. Por exemplo, o retardo de cicatrização, como ocorre no caso de úlceras de pés diabéticos, constitui grave problema mundial, tanto financeiro quanto social. Dados dos Estados Unidos informam que $15,5 \%$ da população mundial com idade superior a 30 anos é composta de diabéti$\cos$, dos quais cerca de $15 \%$ desenvolvem úlceras de difícil cicatrização ao longo da vida, principalmente, nos membros inferiores. Assim, 6\% das internações hospitalares relacionadas aos diabéticos são conse- quência dessas úlceras e, em caso de amputação, o tempo médio de internação é de cerca de três semanas. Esses casos geram para os sistemas de saúde custo extra que varia de U\$8.000 a U\$12.000/paciente. Dos amputados vão a óbito em cinco anos cerca de 39 a $68 \% .^{1}$ No Brasil estima-se a existência de dois milhões de casos, entre os aposentados e os que recebem auxílios-doença em função da diabetes. ${ }^{2}$

A cicatrização de feridas é processo complexo que envolve a organização de células, sinais químicos e matriz extracelular com o objetivo de reparar o tecido. Por sua vez, o tratamento de feridas busca o fechamento rápido da lesão de forma a se obter cicatriz funcional e esteticamente satisfatória. Para tanto, é indis-

\footnotetext{
Aprovado pelo Conselho Editorial e aceito para publicação em 08.12.2008

* Trabalho realizado no Departamento de Bioquímica e Imunologia da Faculdade de Medicina de Ribeirão Preto - Universidade de São Paulo (USP) - Ribeirão Preto (SP), Brasil.

Conflito de interesse: Nenhum / Conflict of interest: None

Suporte financeiro / Financial funding: Coordenação de Aperfeiçoamento de Pessoal de Nível Superior - Capes e Fundação de Apoio ao Ensino, Pesquisa e Assistência - Faepa.

Pós-doutorando do Departamento de Bioquímica e Imunologia da Faculdade de Medicina de Ribeirão Preto - Universidade de São Paulo (USP) - Ribeirão Preto (SP), Brasil.

Professor-associado do Departamento de Bioquímica e Imunologia da Faculdade de Medicina de Ribeirão Preto - Universidade de São Paulo (USP) - Ribeirão Preto (SP), Brasil. 
pensável melhor compreensão do processo biológico envolvido na cicatrização de feridas e regeneração tecidual. ${ }^{3}$

Com o rompimento tecidual nos animais vertebrados, logo se inicia o processo de reparo, que compreende uma sequência de eventos moleculares objetivando a restauração do tecido lesado. Só durante a fase fetal o reparo de lesões se dá sem a formação de cicatriz, ocorrendo perfeita restauração do tecido pelo processo de neoformação tecidual. Após o nascimento, o organismo falha nesse processo, desenvadeando a formação da cicatriz após o reparo. ${ }^{4-5}$

\section{CLASSIFICAÇÃO DOS PROCESSOS BIOLÓGICOS DA CICATRIZAÇÃO}

O processo de cicatrização tem sido convenientemente dividido em três fases que se sobrepõem de forma contínua e temporal: inflamatória, proliferativa e de remodelagem. ${ }^{6}$

\section{1- Fase inflamatória}

Após a ocorrência do ferimento, inicia-se o extravasamento sanguíneo que preenche a área lesada com plasma e elementos celulares, principalmente plaquetas. A agregação plaquetária e a coagulação sanguínea geram um tampão, rico em fibrina, que além de restabelecer a hemostasia e formar uma barreira contra a invasão de microrganismos, organiza matriz provisória necessária para a migração celular. Essa matriz servirá também, como reservatório de citocinas e fatores de crescimento que serão liberados durante as fases seguintes do processo cicatricial.7-8

As plaquetas, essenciais à formação desse tampão hemostático, também secretam múltiplos mediadores, incluindo fatores de crescimento, liberados na área lesada. Induzidas pela trombina, ainda sofrem a degranulação plaquetária e liberam vários fatores de crescimento, como o derivado de plaquetas (PDGF), o de crescimento transformante- $\beta$ (TGF- $\beta$ ), o de crescimento epidérmico (EGF), o de crescimento transformante-a (TGF- $\alpha$ ) e o fator de crescimento de células endoteliais (VEGF), além de glicoproteínas adesivas como a fibronectina e trombospondina, que são importantes constituintes da matriz extracelular provisória. ${ }^{9-10}$ Mais ainda, a ativação da cascata de coagulação e do complemento, juntamente com a liberação dos fatores de crescimento e ativação de células parenquimatosas pela lesão, produz numerosos mediadores vasoativos e fatores quimiotáticos que auxiliam o recrutamento das células inflamatórias no local da ferida. ${ }^{6}$

Após a saída das plaquetas de dentro do leito vascular, neutrófilos e monócitos, em resposta aos agentes quimiotáticos, migram em direção ao leito da ferida. ${ }^{6}$ A ausência dos neutrófilos no sangue, porém, parece não afetar o processo de reparo na ausência de infecção. ${ }^{8,11-12}$ No gráfico 1 é apresentada a especificidade celular no decorrer da cicatrização. ${ }^{13}$

Além da função de fagocitose de bactérias, fragmentos celulares e corpos estranhos, essas células inflamatórias produzem fatores de crescimento, que preparam a ferida para a fase proliferativa, quando fibroblastos e células endoteliais também serão recrutados. ${ }^{3}$ (Gráfico 1)

Os monócitos do sangue periférico, tanto inicialmente quanto durante o transcorrer do processo cicatricial, continuam a infiltrar-se no local da ferida em resposta a agentes quimiotáticos para monócitos, como o PDGF, por exemplo. A liberação dos fatores provenientes das plaquetas, assim como a fagocitose dos componentes celulares, como fibronectina ou colágeno, contribuem também para a ativação dos monócitos, transformando-os em macrófagos que são as principais células envolvidas no controle do processo de reparo. 3,6

O macrófago ativado é a principal célula efetora do processo de reparo tecidual, degradando e removendo componentes do tecido conjuntivo danificado, como colágeno, elastina e proteoglicanas. Além desse papel na fagocitose de fragmentos celulares, os macrófagos também secretam fatores quimiotáticos que atraem outras células inflamatórias ao local da ferida e produzem prostaglandinas, que funcionam como potentes vasodilatadores, afetando a permeabilidade dos microvasos.3,10-11 Os macrófagos produzem vários fatores de crescimento, tais como o PDGF, o TGF- $\beta$, o fator de crescimento de fibroblastos (FGF) e o VEGF, que se destacam como as principais citocinas necessárias para estimular a formação do tecido de granulação. ${ }^{3}$

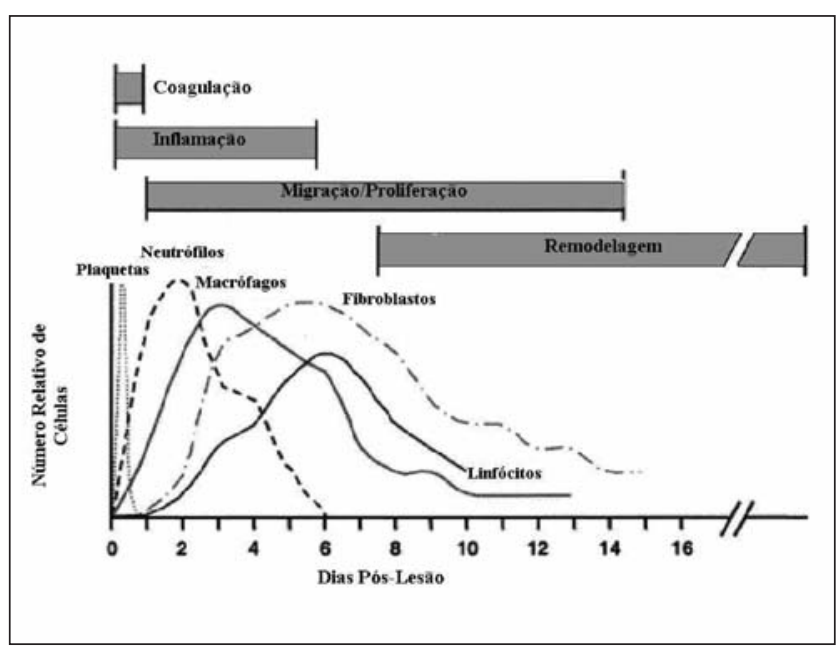

Gráfico 1: Representação esquemática da especificidade celular imunológica correlacionada temporalmente com as fases da cicatrização

Fonte adaptada: Park JE, Barbul A1 ${ }^{3}$ 


\section{2- Fase proliferativa}

A proliferação é a fase responsável pelo fechamento da lesão propriamente dito. Compreende: reepitelização, que se inicia horas após a lesão, com a movimentação das células epiteliais oriundas tanto da margem como de apêndices epidérmicos localizados no centro da lesão; fibroplasia e angiogênese, que compõem o chamado tecido de granulação responsável pela ocupação do tecido lesionado cerca de quatro dias após a lesão. Os fibroblastos produzem a nova matriz extracelular necessária ao crescimento celular enquanto os novos vasos sanguíneos carreiam oxigênio e nutrientes necessários ao metabolismo celular local. ${ }^{3}$

A fase de proliferação epitelial, no caso da pele, inicia-se por estimulação mitogênica e quimiotática dos queratinócitos pelo TGF- $\alpha$ e EGF. Tão importante quanto a epitelização, que começa nessa fase do processo de reparo, é a formação do chamado tecido de granulação, nome atribuído sobretudo pela característica granular devida à presença de novos capilares neoformados essenciais ao processo de reparo. ${ }^{14}$

Antes de descrever a angiogênese, cabe salientar que o aumento da permeabilidade microvascular é o primeiro estádio desse processo, apresentando-se como etapa importante, que permite, através do extravasamento de proteínas, citocinas e elementos celulares, a formação de matriz extracelular provisória necessária à migração e proliferação das células endoteliais. ${ }^{15-16}$

\section{1- Permeabilidade vascular}

A produção de novos vasos sanguíneos a partir de vasos preexistentes é acompanhada, na maioria das vezes, por aumento da permeabilidade vascular. ${ }^{15-17}$ $\mathrm{Na}$ angiogênese patológica, o aumento da permeabilidade vascular à água e às macromoléculas apresenta importante função no processo, sendo o responsável direto pela formação do edema. Esse aumento da permeabilidade capilar parece ter menor efeito durante a angiogênese fisiológica, porém, causa danos consideráveis em determinadas patologias, como a retinopatia diabética, por exemplo. ${ }^{18}$

Várias citocinas produzidas durante o processo de cicatrização interferem diretamente na permeabilidade vascular. O VEGF-A, por exemplo, descoberto em líquido ascítico tumoral, foi originalmente descrito por sua capacidade de aumentar a permeabilidade dos microvasos e o extravasamento de macromoléculas, incluindo fibrinogênio e outras proteínas da coagulação. O extravasamento dessas proteínas resultam na deposição extravascular de fibrina, favorecendo tanto o processo cicatricial quanto o desenvolvimento tumoral. ${ }^{15}$

Os mecanismos básicos da regulação da permeabilidade vascular, causada principalmente pelos fatores de crescimento, não foram ainda completamente elucidados. ${ }^{15,19}$ Alguns pesquisadores, porém, acreditam que as células endoteliais tenham sua contração induzida pelos agentes permeabilizantes, formando espaços (gaps) intercelulares de tamanho suficiente para permitir o extravasamento de proteínas plasmáticas. ${ }^{20-21}$ Mais recentemente, a descoberta de uma estrutura no endotélio venoso, a organela vesiculovacuolar, ofereceu via transendotelial alternativa para o extravasamento de proteínas plasmáticas em resposta a fatores de permeabilidade. ${ }^{21-23}$

\section{2- Angiogênese}

A angiogênese é etapa fundamental do processo de cicatrização, na qual novos vasos sanguíneos são formados a partir de vasos preexistentes. ${ }^{24}$ Os novos vasos participam da formação do tecido de granulação provisório e suprem de nutrientes e de oxigênio o tecido em crescimento. ${ }^{25}$ De forma diferencial, a vasculogênese refere-se aos primeiros estádios do desenvolvimento vascular, durante o qual as células precursoras do endotélio vascular sofrem diferenciação, expansão e coalescência para formar a rede de túbulos primitivos do organismo. ${ }^{26}$

Em um organismo adulto, sob condições normais, a angiogênese só ocorre no ciclo reprodutivo das fêmeas (no útero, com a formação do endométrio, e nos ovários, na formação do corpo lúteo). Dessa forma, a rede vascular se mantém quiescente, porém apresentando a capacidade de iniciar a angiogênese, principalmente durante a cicatrização. ${ }^{25}$

Em resposta à lesão tecidual, a angiogênese é processo dinâmico, finamente regulado por sinais presentes tanto no soro quanto na matriz extracelular local. ${ }^{26}$ Durante o processo cicatricial, a formação de novos vasos sanguíneos torna-se necessária para a formação do novo tecido de granulação, correspondendo as células dos vasos sanguíneos a cerca de $60 \%$ do tecido de reparo. ${ }^{10} \mathrm{~A}$ angiogênese ocorre na matriz extracelular do leito da ferida com a migração e estimulação mitogênica das células endoteliais.

A indução da angiogênese foi inicialmente atribuída ao FGF ácido ou básico. Subsequentemente, muitas outras moléculas foram identificadas, como angiogênicas, incluindo o VEGF, TGF- $\beta$, angiogenina, angiotropina e angiopoetina-1. ${ }^{27}$ Baixa tensão de oxigênio ${ }^{28}$ e elevados níveis de ácido lático e aminas bioativas $^{29}$ também podem estimular a angiogênese. Muitas dessas moléculas são proteínas e parecem induzir a angiogênese de forma indireta, estimulando a produção de FGF ácido ou básico e VEGF por macrófagos e células endoteliais, indutores diretos da angiogênese.

\section{3- Matriz extracelular}

Para que ocorra a migração das células endoteliais e o desenvolvimento de novos capilares de estru- 
tura tubular há dependência não só das células e citocinas presentes, mas também de uma produção e organização dos componentes da matriz extracelular, incluindo fibronectina, colágeno, vibronectina, tenascina e laminina, tanto no tecido de granulação quanto na membrana endotelial basal. A matriz extracelular é importante para o crescimento e manutenção normal dos vasos, pois, além de agir como "plataforma" que dá suporte à migração celular, age também como reservatório e modulador da liberação de fatores de crescimento, como o FGF2 e o TGF- $\beta .30$

A proliferação das células endoteliais adjacentes e dentro da ferida leva à deposição, de forma transitória, de grandes quantidades de fibronectina na parede do vaso. ${ }^{6}$ Assim, a angiogênese requer a expressão de receptores para fibronectina pelas células endoteliais, ${ }^{31}$ organizando a fibronectina como um canal, de modo a permitir o movimento das células endoteliais. Expressão e atividade de proteases também são necessárias à angiogênese, principalmente na fase de remodelagem. ${ }^{6}$

\section{3- Fase de remodelagem}

Nessa fase do processo de cicatrização ocorre uma tentativa de recuperação da estrutura tecidual normal. É fase marcada por maturação dos elementos e alterações na matriz extracelular, ocorrendo o depósito de proteoglicanas e colágeno. Em fase mais tardia, os fibroblastos do tecido de granulação transformamse em miofibroblastos comportando-se como um tecido contrátil responsivo aos agonistas que estimulam o músculo liso. Ocorre, concomitantemente, reorganização da matriz extracelular, que se transforma de provisória em definitiva, cuja intensidade fenotípica, observada nas cicatrizes, reflete a intensidade dos fenômenos que ocorreram, bem como o grau de equilíbrio ou desequilíbrio entre eles. 32

Com o decorrer do processo de maturação e remodelagem, a maioria dos vasos, fibroblastos e células inflamatórias desaparece do local da ferida mediante processos de emigração, apoptose ou outros mecanismos desconhecidos de morte celular. Esse fato leva à formação de cicatriz com reduzido número de células. Por outro lado, se persistir a celularidade no local, ocorrerá a formação de cicatrizes hipertróficas ou queloides. ${ }^{10}$

As principais citocinas envolvidas nessa fase são: fator de necrose tumoral (TNF- $\alpha$ ), interleucina (IL-1), PDGF e TGF- $\beta$ produzidas pelos fibroblastos, além das produzidas pelas células epiteliais como EGF e TGF-b. 33

A reepitelização, que é o recobrimento da ferida por novo epitélio e consiste tanto na migração quanto na proliferação dos queratinócitos a partir da periferia da lesão, também ocorre durante a fase pro- liferativa. Esses eventos são regulados por três principais agentes: fatores de crescimento, integrinas $\mathrm{e}$ metaloproteases. ${ }^{34}$

Durante a fase inflamatória a liberação de fatores de crescimento por plasma, fibroblastos e macrófagos/neutrófilos ativa os queratinócitos localizados nas margens e no interior do leito da ferida. Dentre os fatores de crescimento destacam-se o PDGF, que induz a proliferação de fibroblastos com consequente produção da matriz extracelular durante a contração da ferida e reorganização da matriz, $\mathrm{O} \mathrm{KGF}_{7}$, que é considerado o principal regulador da proliferação dos queratinócitos, assim como o TGF- $\beta$, principal responsável pelo estímulo inicial da migração das células epiteliais. A ativação de receptores de integrinas pelos queratinócitos permite a interação com uma variedade de proteínas da matriz extracelular na margem e no leito da ferida. Por outro lado, a expressão e ativação de metaloproteases promovem a degradação e modificação das proteínas da matriz extracelular no sítio da ferida, facilitando a migração celular. A própria atividade proteolítica dessas enzimas pode liberar fatores de crescimento ligados à matriz extracelular, de forma a manter constante o estímulo à proliferação e migração dos queratinócitos, acelerando o processo de reepitelização. ${ }^{34}$

Várias são as doenças que interferem negativamente no processo de reparo tecidual, como diabetes, esclerose sistêmica, anemia, desnutrição, entre outras. Muitas também são as condições que tornam esse processo de difícil resolução, impedindo ou retardando a completa restauração dos tecidos. Dentre essas condições podem ser ressaltadas as ressecções extensas da parede abdominal, como aquelas em que a peritoniostomia se faz necessária. Por dificultarem, de alguma maneira, o reparo tecidual, essas doenças contribuem potencialmente para o aumento da morbidade e mortalidade. ${ }^{35-36}$

Nas últimas décadas, vários estudos têm sido realizados no sentido de identificar substâncias capazes de favorecer o processo de reparo. Também a busca de substâncias com atividade angiogênica tem sido intensa, por seu grande potencial de aplicação clínica.

Dentre as substâncias que possuem ação direta no processo de reparo destacam-se alguns fatores de crescimento que, quando aplicados topicamente sobre a ferida, demonstram boa capacidade de acelerar o reparo tecidual em experimentos animais. ${ }^{37-39}$ Nesse grupo, merece destaque o REGRANEX“, produto à base de PDGF recombinante humano, que interfere diretamente de maneira a favorecer o processo de reparo, apresentando bons resultados na cicatrização de úlceras de pacientes diabéticos. ${ }^{39-40}$ No entanto, são curativos de alto custo, que se encontram distan- 
tes da realidade socioeconômica da maioria da população portadora de úlceras crônicas. Outras substâncias contendo agentes enzimáticos como as pomadas à base de DNAse e colagenase atuam promovendo o debridamento da ferida ${ }^{41}$ e auxiliam, dessa forma, o curso da restauração tecidual de maneira discreta e indireta. Estas últimas, embora largamente utilizadas na prática clínica, apresentam baixa eficácia na cicatrização de feridas crônicas.

\section{AGRADECIMENTOS}

Os autores agradecem à Coordenação de Aperfeiçoamento de Pessoal de Nível Superior (Capes) e Fundação de Apoio ao Ensino, Pesquisa e Assistência (Faepa) o apoio financeiro.

\section{REFERÊNCIAS}

1. Brod M. Quality of life issues in patients with diabetes and lower extremity ulcer: patients and care givers. Qual Life Res. 1998;7:365-72.

2. Toscano MC, Mengue, SS. Avaliação do plano de reorganização da atenção à hipertensão arterial e ao diabetes mellitus no Brasil/Ministério da Saúde - Organização Pan-Americana da Saúde Brasilia; ed MS, 2004. p.13.

3. Singer AJ, Clark RA. Cutaneous wound healing. N Engl J Med. 1999;341:738-46.

4. Martin P, Leibovich SJ. Inflammatory cells during wound repair: the good, the bad and the ugly. Trends Cell Biol. 2005;15:599-607.

5. Mccallion RL, Ferguson. Fetal wound healing and development of antiscarring therapies for adult wound healing. In: Clark RA, ed. The molecular and cellular biology of wound repair 2ed. New York: Plenum Press; 1996. p.561-90.

6. Clark RA. The molecular and cellular biology wound repair. 2nd ed. New York: Plenum Press; 1996.

7. Eming SA, Krieg T, Davidson JM. Gene therapy and wound healing. Clin Dermatol. 2007;25:79-92.

8. Werner S, Grose R. Regulation of wound healing by growth factors and cytokines. Physiol Rev. 2003;83:835-70.

9. Streit M, Velasco P, Riccardi L, Spencer L, Brown LF, Janes L, et al. Thrombospondin-1 suppresses wound healing and granulation tissue formation in the skin of transgenic mice. EMBO J. 2000;19:3272-82.

10. Arnold F, West DC. Angiogenesis in wound healing. Pharmacol Ther. 1991;52:407-22.

11. Eming SA, Werner S, Bugnon P, Wickenhauser C, Siewe $\mathrm{L}$, Utermohlen $\mathrm{O}$, et al. Accelerated wound closure in mice deficient for interleukin-10. Am J Pathol. 2007;170:188-202.

12. Simpson DM, Ross R. The neutrophilic leukocyte in wound repair a study with antineutrophil serum. J Clin Invest. 1972;51:2009-23.

13. Park JE, Barbul A. Understanding the role of immune regulation in wound healing. Am J Surg. 2004;187:S11-6.
14. Frade MA. Úlcera de perna: caracterização clínica e perfil imunohistopatológico do reparo tecidual na presença da biomembrana de látex natural da seringueira Hevea brasiliensis. Ribeirão Preto: Faculdade de Medicina de Ribeirão Preto - USP; 2003.

15. Dvorak HF. Vascular permeability factor/vascular endothelial growth factor: a critical cytokine in tumor angiogenesis and a potential target for diagnosis and therapy. J Clin Oncol. 2002;20:4368-80.

16. Dvorak HF, Nagy JA, Feng D, Brown LF, Dvorak AM. Vascular permeability factor/vascular endothelial growth factor and the significance of microvascular hyperpermeability in angiogenesis. Curr Top Microbiol Immunol. 1999;237:97-132.

17. Bates DO, Harper SJ. Regulation of vascular permeability by vascular endothelial growth factors. Vascul Pharmacol. 2002;39:225-37.

18. Vaquero J, Zurita M, Morales C, Cincu R, Oya S. Expression of vascular permeability factor in glioblastoma specimens: correlation with tumor vascular endothelial surface and peritumoral edema. J Neurooncol. 2000;49:49-55.

19. Dvorak HF. Angiogenesis: update 2005. J Thromb Haemost. 2005;3:1835-42.

20. Majno G, Shea SM, Leventhal M. Endothelial contraction induced by histamine-type mediators: an electron microscopic study. J Cell Biol. 1969;42:647-72.

21. Nagy JA, Benjamin L, Zeng H, Dvorak AM, Dvorak HF. Vascular permeability, vascular hyperpermeability and angiogenesis. Angiogenesis. 2008

22. Dvorak AM, Kohn S, Morgan ES, Fox P, Nagy JA, Dvorak HF. The vesiculo-vacuolar organelle (VVO): a distinct endothelial cell structure that provides a transcellular pathway for macromolecular extravasation. J Leukoc Biol. 1996;59:100-15.

23. Feng D, Nagy JA, Dvorak AM, Dvorak HF. Different pathways of macromolecule extravasation from hyperpermeable tumor vessels. Microvasc Res. 2000;59:24-37. 
24. Folkman J, Shing Y. Angiogenesis. J Biol Chem. 1992;267:10931-4.

25. Li J, Foitzik K, Calautti E, Baden H, Doetschman T, Dotto GP. TGF-beta3, but not TGF-beta1, protects keratinocytes against 12-O-tetradecanoylphorbol13-acetate-induced cell death in vitro and in vivo. $\mathrm{J}$ Biol Chem. 1999;274:4213-9.

26. Risau W. Mechanisms of angiogenesis. Nature. 1997;386:671-4.

27. Folkman J, D'Amore PA. Blood vessel formation: what is its molecular basis? Cell. 1996;87:1153-5.

28. Detmar M, Brown LF, Berse B, Jackman RW, Elicker BM, Dvorak HF, et al. Hypoxia regulates the expression of vascular permeability factor/vascular endothelial growth factor (VPF/VEGF) and its receptors in human skin. J Invest Dermatol. 1997;108:263-8.

29. Remensnyder JP, Majno G. Oxygen gradients in healing wounds. Am J Pathol. 1968;52:301-23.

30. Ruoslahti E, Yamaguchi Y. Proteoglycans as modulators of growth factor activities. Cell. 1991;64:867-9.

31. Brooks PC, Clark RA, Cheresh DA. Requirement of vascular integrin alpha $\mathrm{v}$ beta 3 for angiogenesis. Science New York, NY. 1994;264:569-71.

32. Gabbiani G, Hirschel BJ, Ryan GB, Statkov PR, Majno G. Granulation tissue as a contractile organ. A study of structure and function. J Exp Med. 1972;135:719-34.

33. Karukonda SR, Flynn TC, Boh EE, McBurney EI, Russo GG, Millikan LE. The effects of drugs on wound healing--part II. Specific classes of drugs and their effect on healing wounds. International journal of dermatology. 2000;39:321-33.

34. Santoro MM, Gaudino G. Cellular and molecular facets of keratinocyte reepithelization during wound healing. Exp Cell Res. 2005;304:274-86.

35. Mrué F. Neoformação tecidual induzida por biomembrana de látex natural com poli-lisina. Aplicabilidade na neoformação esofágica e da parede abdominal. Estudo experimantal em cães. Ribeirão Preto: Faculdade de Medicina de Ribeirão Preto - USP; 2000.
36. Mrué F, Coutinho-Netto J, Ceneviva R, Lachat JJ, Thomazini JA, Tambelini H. Evaluation of the biocompatibility of a new biomembrane. Materials Research. 2004;7:277-83

37. Mustoe TA, Pierce GF, Morishima C, Deuel TF. Growth factor-induced acceleration of tissue repair through direct and inductive activities in a rabbit dermal ulcer model. J Clin Invest. 1991;87:694-703.

38. Pierce GF, Tarpley JE, Allman RM, Goode PS, Serdar CM, Morris B, et al. Tissue repair processes in healing chronic pressure ulcers treated with recombinant plateletderived growth factor BB. Am J Pathol. 1994;145:1399-410.

39. Pierce GF, Tarpley JE, Yanagihara D, Mustoe TA, Fox GM, Thomason A. Platelet-derived growth factor (BB homodimer), transforming growth factor-beta 1, and basic fibroblast growth factor in dermal wound healing. Neovessel and matrix formation and cessation of repair. Am J Pathol. 1992;140:1375-88.

40. Steed DL. Modifying the wound healing response with exogenous growth factors. Clin Plast Surg. 1998; 25: 397-405.

41. Hebda PA, Klingbeil CK, Abraham JA, Fiddes JC. Basic fibroblast growth factor stimulation of epidermal wound healing in pigs. J Invest Dermatol. 1990;95:626-31.

\author{
ENDEREÇO PARA CORRESPONDÊNCIA / MAILING ADDRESS: \\ Ricardo José de Mendonça \\ Universidade de São Paulo - Faculdade de \\ Medicina de Ribeirão Preto - Departamento de \\ Bioquímica e Imunologia \\ Av. Bandeirantes, 3900 . \\ 14040900 Ribeirão Preto SP \\ Tel./fax: 16 3602-3321 $163633-6840$ \\ e-mail:rjmendonca2000@yahoo.com.br
}

Como citar este artigo/How to cite this article: Mendonça RJ, Coutinho-Netto J. Aspectos celulares da cicatrização. An Bras Dermatol. 2009;84(3):257-62. 